\title{
Correction to: Answer Set Programming for Declarative Content Specification: A Scalable Partitioning-Based Approach
}

Francesco Calimeri (D), Stefano Germano (D), Giovambattista Ianni (D), Francesco Pacenza (D), Armando Pezzimenti (D), and Andrea Tucci (D)

\section{Correction to:}

Chapter "Answer Set Programming for Declarative Content Specification: A Scalable Partitioning-Based Approach" in:

C. Ghidini et al. (Eds.): AI*IA 2018 - Advances in Artificial Intelligence, LNAI 11298, https://doi.org/10.1007/978-3-030-03840-3_17

The original version of the chapter "Answer Set Programming for Declarative Content Specification: A Scalable Partitioning-Based Approach" starting on p. 225 has been revised. The corresponding author name was wrongly identified and affiliations were incorrect and should be read as follows:

Francesco Calimeri, Stefano Germano, Giovambattista Ianni, Francesco Pacenza (Corresponding Author), Armando Pezzimenti, and Andrea Tucci

Department of Mathematics and Computer Science, University of Calabria, Rende, Italy \{calimeri,germano,ianni,pacenza\}@mat.unical.it, armnd.6793@gmail.com, andrea.tucci.cs@gmail.com

The original chapter was corrected.

The updated version of this chapter can be found at https://doi.org/10.1007/978-3-030-03840-3_17 